\title{
ESCREVER SOBRE O ESCREVER
}

\section{Margareth Schäffer \\ Universidade Federal do Rio Grande do Sul, Porto Alegre, Brasil}

RESUMO: O objetivo deste texto é propor uma problematização a respeito da escrita e do escrito, cuja incidência específica, por decorrência, dá-se na escrita escolar. Procuro demarcar a polissemia e a impossibilidade que a escrita convoca, valendo-me de vários autores, principalmente Fernando Pessoa e Jacques Lacan. Assinalo, ainda, alguns desdobramentos possíveis entre escrita, escrito, escritura, inscrição e criação.

PALAVRAS-CHAVE: Palavra, escrita, criação.

\section{WRITING ABOUT THE ACT OF WRITING}

ABSTRACT: This text aims to discuss theoretical problematizations about the act of writing, relating this subject with writing experiences in school. The principal references are concepts of Jacques Lacan and Fernando Pessoa texts about the act of writing. The article puts forward the argument that writing is a complex issue, considering its condition of real "impossibility" and the difficulties that reality of polysemy brings to us. Finally, the author establishes relations between writing, écriture, creation and inscription.

KEYWORDS: Words, writing, creation.

Na palavra falada temos que ser, em absoluto, do nosso tempo e lugar; não podemos falar como Vieira, pois nos arriscamos ou ao ridículo ou à incompreensão. Não podemos pensar como Descartes, pois nos arriscamos ao tédio alheio. A palavra escrita, ao contrário, não é para quem a ouve, busca quem a ouça; escolhe quem a entenda, e não se subordina a quem a escolhe. Na palavra escrita tem tudo que estar explicado, pois o leitor nos não pode interromper com o pedido de que nos expliquemos melhor. Desejo ser um criador de mitos, que é o mistério mais alto que pode obrar alguém da humanidade.

Deve cada um de nós fazer por em si realizar o máximo que pode de semelhante ao Desejado. A soma, a confluência, a sintese por assim dizer carnal dessas ânsias será a pessoa do Encoberto.

(Fernando Pessoa. O livro do desassossego)

Palavra, escrita, mito, criação, Desejado, Encoberto. A estas palavras podemos acrescentar outras, mas creio que a série que formam já nos lança a uma árdua tarefa, que é a de verter as mesmas para um texto, escrito. Escrever sobre a escrita, escrita sobre escrita, e tecer a escrita com a criação, criação de mitos, como quer Pessoa - esta parece-nos uma obra em excesso. Muita tinta já correu, escorreu sobre o papel, acerca da escrita e da criação. O que pode, ainda, advir acerca dessa problemática? Será que existe uma teoria da escrita $^{1}$ e da criação ${ }^{2}$ ? Pergunto, pois os dois significantes fazem nó quando ocupam um lugar na educação escolar (não só nela, certamente). Para usar a palavra do poeta português acima citado, é da pessoa do Encoberto que estamos falando, dessa que Deseja. Mas qual o lugar que a pessoa do Encoberto, daquela que Deseja, pode ter na Escola, na escrita escolar, na escrita/inscrição do sujeito, na sua criação como Desejante? E será que podemos falar de escrita/inscrição e de criação quando nos referimos à escola e a seus sujeitos? O que pode ter a escrita escolar de inscrição de si? Não será forçar em demasia ler um lugar de escrita por outro lugar de escrita? Fernando Pessoa, nas citações acima, certamente está falando de literatura, mas em que pese o desconhecimento de sua obra lingüística ${ }^{3}$, ele também fala de teoria da linguagem, da língua, da palavra e da escrita.

Minhas reflexões, neste texto, se dirigem a uma problematização da escrita, cuja incidência específica, por respingos, é a escrita escolar. Sabemos o quão interessante podem ser as perguntas acerca da origem da escrita ou da criação, mas também sabemos que da origem pouco ou nada pode ser dito. Provavelmente, porque é do vazio que se trata, do entre-duas-mortes de Lacan, da pulsão de morte em Freud, de um mito como quer Pessoa, enfim, de uma ficção. Borges, ao escrever sobre o ofício do verso, diz: "Creio que Emerson escreveu em algum lugar que uma biblioteca é um tipo de caverna mágica cheia de mortos. E aqueles mortos podem ser ressuscitados, podem ser trazidos de volta à vida quando se abrem suas páginas" (2000, p.12). Sem adentrarmos na questão do livro, da leitura do livro com que ele nos acena, recortemos a metáfora da caverna mágica de mortos e imaginemos que a escola, com sua biblioteca, seus alunos, sua escrita legível/ 
gráfica, é esse lugar do qual fala Borges. Como fazer aparecer o leitor "certo", a poesia por trás das palavras, para que haja um salto para a vida - a ressurreição da palavra? Mas isso não seria arriscar o impossível, ou seja, não seria um excesso querer ressuscitar a palavra através do leitor "certo"? Retornaremos a este ponto mais adiante. Sigamos.

Gagnebin, em Lembrar escrever esquecer, nos diz que, desde Platão, a oralidade representa a vivacidade de uma busca comum da verdade, enquanto a escrita, por sua vez, "deseja perpetuar o vivo, mantendo sua lembrança para as gerações futuras, mas só pode salvá-lo quando o codifica e o fixa, transformando sua plasticidade em rigidez, afirmando e confirmando sua ausência - quando pronuncia sua morte" (2006, p. 11). Já é lugar comum dizer que a escrita é o lugar da morte, pois que mata a palavra viva, oral; mas ao fazê-lo deseja, paradoxalmente, perpetuar o vivo. Isso nos leva a pensar que, mesmo sendo a escrita o lugar da morte, que desenha o vulto da ausência, não há garantias de sua perpetuação, já que inscrever/escrever a escrita apenas testemunha "o esplendor e a fragilidade da existência, e do esforço de dizê-la" (2006, p. 11). Fragilidade da escrita, fragilidade do sujeito, os quais só se inscrevem por traços, por rastros que deixam atrás de si. Tais tentativas de inscrição acabam oferecendo pistas sobre os processos de "subjetivação" ${ }^{4}$, os quais são objetos da reflexão contemporânea acerca do sujeito. Até o momento, estava em jogo a escrita/inscrição, o traço, o mito, a criação. Entrou em cena o sujeito (sujeito da escrita?). Aqui, então, peço licença ao leitor para fazer um pequeno desvio de rota, para depois retornarmos às nossas reflexões acerca da escrita e criação.

Quando falamos de sujeito, sempre nos arriscamos a cometer equívocos ou mal-entendidos. Não é somente uma questão de polissemia que entra em questão, mas toda a tradição filosófica ${ }^{5}$ acerca do sujeito. Impossível delimitar um sentido unívoco, do qual nós compartilharíamos. Se eu falo de sujeito da escrita, sujeito do inconsciente, sujeito do conhecimento, entre outros, certamente não estou falando da mesma coisa. Entretanto, não me parece impossível escolher um lugar para falar do sujeito. Escolhi acompanhar o raciocínio de Zizek (2006), que faz uma leitura lacaniana do sujeito, descentrando-o do lugar de entidade substancial ou lócus específico. Diz ele:

O sujeito existe, antes, como uma dimensão eterna de resistência-excesso em relação a todas as formas de subjetivação. O sujeito é um vazio constitutivo básico que impulsiona a subjetivação, mas não pode, em última instância, ser preenchido por ela. É por isso que o signo lacaniano do sujeito é \$ (o sujeito barrado, vazio). (...) Ao mesmo tempo, é por essa própria resistência-excesso diante da subjetivação (...) que os seres humanos estão essencialmente abertos à possibilidade de desenvolver novas formas de subjetivação. Assim, o sujeito é, simultaneamente, a condição transcedental de possibilidade e impossibilidade de todas as formas de subjetivação contingente. (Zizek, 2006, p. 12).

Creio que a longa citação se torna mais pertinente se não perdermos de vista que Zizek está se referindo ao que chamamos de experiência de subjetividade, onde os sujeitos tenham o direito de narrar sua ficção, sua versão dos acontecimentos, ou seja, é a dimensão ética que está em questão, sem a qual não há possibilidade de criação. Não perdendo de vista que essa é a versão de Zizek acerca de Lacan, podemos então convidar o próprio a se pronunciar, não antes de acentuar que o autor não considera que Lacan seja um poeta da falha, por conta de sua concepção de sujeito, de falta, de Real. Antes disso, ele diz que "devemos rejeitar a idéia de uma poesia da falha. Para Lacan não é esse tipo de Coisa-em-si da qual não podemos nos aproximar; é, antes, a liberdade como um corte radical na textura da realidade." (Zizek 2006, p. 205).

Zizek nos faz um convite a arriscar o impossível das formas de subjetivação, mesmo sabendo dos seus limites. Aliás, esse é o título da obra que usamos como referência para fazer as citações acima. O subtítulo é Conversas com Zizek. Encontramos, nas conversas do livro, o autor afirmando que o problema da escrita não é sua inibição, mas sim o seu excesso; escrever demais, detestar escrever. Talvez seja por essa razão que ele não se recusa a eleger uma causa - Lacaniana; ou seja, não se recusa a arriscar o impossível. Estabelecida a concepção de sujeito que colocamos em causa, podemos retornar ao impossível da escrita e criação, causa de nosso desvio.

Enlaçando agora escrita, criação e sujeito, podemos pensar numa tessitura mais delicada, tal qual a teia de aranha que Joyce ${ }^{6}$ tem desenhado no seu peito, quadro que ele solicitou que fosse feito em forma de ponto de interrogação.Certa vez, indagado sobre se poderiam fazer uma fotografia sua, Joyce responde o seguinte: você quer fotografar a mim ou ao meu escrito? Teia de aranha, ponto de interrogação, escrita, sujeito. É dessa forma que eu vejo muitas crianças se depararem com os escritos escolares; ou a nós mesmos, frente a um texto por ser escrito. Para Gagnebin, "Como pode traduzir/ transcrever a linguagem oral, a escrita se relaciona essencialmente com o fluxo narrativo que constitui nossas histórias, nossas memórias, nossa tradição e nossa identidade." (2006, p. 111). Quando tantas coisas se entrecruzam para produzir uma escrita, quer seja do texto ou de uma escrita de si, fica difícil pensar somente em uma impressão gráfica, literal. Existe o traço, o rastro que não podem ser confundidos com um escrito gráfico e de referência lingüística clara. Assim, "Rigorosamen- 
te falando, rastros não são criados - como são outros signos culturais e lingüísticos -, mas sim deixados ou esquecidos." (2006, p.113) Desprovido de visada significativa, o rastro chama o detetive, o caçador, o historiador, o psicanalista, enfim, chama alguém, qualquer um; chama Borges para ressuscitar o livro morto, feito de ossos, de traços, que está na biblioteca.

Seguindo ainda Gagnebin, quando nos fala do belo livro de Aleida Assmann, acerca da interpretação das práticas artísticas contemporâneas, encontramos uma transformação do conceito de rastro: "desprovido da durabilidade que poderia ligá-lo à escrita, entregue à caducidade e mesmo à clandestinidade, o rastro se aproxima dos restos, dos detritos, da sucata, do lixo." (2006, p. 117). Entretanto, a autora não desiste da leitura do traço e, valendo-se da figura do narrador autêntico $(\text { Benjamim })^{7}$, anônimo, nos convoca à decifração, apesar de não existir nenhuma certeza de salvação, ainda menos de paraíso: "No entanto, podemos - e talvez mesmo devamos - continuar a decifrar os rastros e colher os restos." (2006, p. 118). Decifrar os rastros e colher os restos parece-me ser uma tarefa que implica profundamente o "sujeito da escrita". A pergunta a ser feita talvez seja esta: o que significa falar em "sujeito da escrita"? Coloco entre aspas para preservar a ambigüidade da expressão, que tanto pode nos conduzir a uma noção de escritura (Derrida), de escrita/inscrição (Lacan), ou de escrita literal (Escola). Entretanto, se definimos o sujeito como nos apresenta Zizek - o sujeito é um vazio aberto à subjetivação -, estamos tomando uma certa acepção do mesmo, a lacaniana. Tal visada já estreita caminhos, mas também nos abre, novamente, a ambigüidade que a expressão "sujeito da escrita" pode tomar. Quando penso nessa expressão, o que está em questão é uma posição de singularidade e criação que o sujeito pode inscrever através da escrita, a qual está aqui referida em dois sentidos, ou seja, escrita/inscrição e escrita/literal. Para Branco, a escrita, "Em sua redução ao puro traço, à pura inscrição, é sulcagem na superfície/ corpo sobre a qual se escreve e se inscreve um sujeito." (2000, p. 23). E, segundo Lacan, em Lituraterra (2003), a escrita é o que faz borda, litoral entre gozo e saber, entre Real e Simbólico, separando e conjugando campos heterogêneos. Em que pese a heterogeneidade das acepções acerca da escrita, mesmo na própria teoria lacaniana ${ }^{8}$ podemos nos propor a ler os rastros, o resto, os intervalos, as hesitações, as rasuras, do escrever sobre o escrever, do sujeito que se inscreve ao realizar a experiência da escrita.

No Livro do Desassossego (1990) ${ }^{9}$, Pessoa de tudo se serviu para inscrever sua exigência de escrita: envelopes de cartas recebidas, folhetos de propaganda, recibos, faturas, até mesmo papel de embrulho foram o suporte de sua escrita. Aqui, novamente, duas possibi- lidades de leitura, inscrição e escrita - escrever sobre o escrever que, no autor, articula-se como Desejo ${ }^{10}$ e pessoa do Encoberto. Um tipo de escrita cheia de rasuras, correções, ocupação de todos os espaços em branco - o que, certamente, exigiu muito trabalho de quem editou a obra-projeto. Pergunta-se Pessoa: "Por que escrevo eu este livro? Porque o reconheço imperfeito. Calado seria a perfeição; escripto, imperfeiçoa-se; por isso o escrevo." (p. 246). Obra, livro, cadernos de aula, todos estão submetidos a estas imperfeições que a escrita tende a velar, embora jamais o consiga. A pessoa do Encoberto advém nos escritos, porque há algo da ordem do desejo que aí pulsa. Acompanho o pensamento de Babo, quando nos diz que

Este livro, que só advém como escrita/escritura após a morte do autor, torna-se, precisamente, por este facto, uma escrita impessoal, a escrita por excelência. Tal é a dimensão que o título imprime ao texto, Mas, ao mesmo tempo que o texto se torna livro, o atributo "livro", no título, negativiza-o, e o livro começa a ser roído por dentro, por uma falha fundamental através da qual, talvez, ele aceda de novo a escrita. Essa falha é o próprio desassossego. (...) dizer do livro que ele é escrita, no sentido de processo, no sentido também em que esta se funda sobre uma falta original, uma perda ou uma privação. (1993, pp. 168-169).

A autora trata da publicação do texto como uma perda - perda da escrita ou escrita da perda. No que concerne a Pessoa, seu texto é uma profunda interrogação sobre o próprio ato de escrita. Tal desafio, o da própria escrita, passa por determinado tipo de configurações, entre as quais a clivagem do sujeito. (1993, p.187). Assim, o Livro do dessassossego não se constitui como uma autobiografia do autor, isso devido "às fracturas que caracterizam o sujeito da escrita, senão a própria escrita." (1993, p.189). Perda, clivagem do sujeito, fraturas, escrita/escritura ${ }^{11}$, vários termos que tentam cingir a escrita ${ }^{12}$, contorná-la, produzir sentido e que acabam, paradoxalmente, assinalando seu nonsense. De uma certa forma, abalo da representação, que mostra o vazio do sujeito, jogo com a morte, já que a escrita funda-se na morte, que dela é condição. Dentre as várias referências que Pessoa faz acerca da escrita, encontramos esta: "E muitos deles (escriptos) me parecem de um extranho; desreconheço-me nelles. Houve quem os escrevesse e fui eu. Senti-os eu, mas foi como em outra vida, de que houvesse agora dispertado como de um sonho alheio." (1990, p. 24). A impressão que nos passa Pessoa é de que isso, os escriptos, não saem dele como sujeito. Talvez por isso, quando escrevemos, descobrimos escrever o que nem sabíamos e o que nem sequer havíamos previsto. Clivagem do sujeito, desdobramento do sujeito sobre si, heterônimos, várias faces a reportar aquilo que de impossível existe na escritura ${ }^{13}$, pois que 
há o véu da linguagem ${ }^{14}$. De outro modo, é interessante sublinhar o que diz Melman no texto A fobia da escrita: "Penso que é um grande passo dado por Lacan nos mostrar que, inclusive no inconsciente, não há escrita que espere algum hermeneuta para poder de maneira válida e responsável, e autorizada, e justificada, nos conduzir." (2004, p. 144). cego. ${ }^{15}$

Desassossego - des-a-so-cego - socego - só e

\section{Sobre alguns conceitos}

Os desdobramentos acerca da questão da escrita não estão dados a uma leitura transparente (véu da linguagem), nem a uma decodificação e nem a um limite conceitual dos mais precisos. Talvez seja próprio do escrito/escrita delinear limites, impossibilidades, permitindo acesso somente quando algo tropeça, faz intervalo (inter-dito). Assim, para Quilichini, "As leis da linguagem não residem mais apenas na metáfora e na metonímia, a cadeia simbólica obedece a impossibilidades de escrita e a uma ordem determinada pela letra" (2004, p. 9). Qual escrita? Qual letra? ${ }^{16}$. Tellermann coloca as mesmas questões: "O problema do estatuto da escrita - do escrito corrente ao escrito literário até a escrita matemática. Trata-se da mesma colocação em jogo da letra?" (2004, p. 43). Trata-se de ir à busca dos conceitos, o que nos permite colocar nossas questões, sem que disso resulte, necessariamente, $O$ conceito. Este, o conceito, é apenas algo para nos virarmos e revirarmos. Quase sempre é o avesso da questão. Mas continuemos nos perguntando sobre a escrita. Vejamos o que diz Darmon:

Logo, isso de fato coloca o problema da escrita. Se no inconsciente caem das cadeias significantes certas letras, podemos ver que isso se concebe antes mesmo que o sujeito aprenda a ler e escrever, de que escrita se trata? Como a letra que colocamos no inconsciente guarda a memória, comemora ela, diz Melman, a cadeia significante da qual ela caiu? E que relação entre essa escrita do inconsciente e a escrita comum? Em algum lugar, acho que é em Sinthoma, Lacan diz: há pessoas que escrevem suas memórias, mas não funciona, da mesma forma que uma análise por escrito não funciona porque se trata da passagem de uma escrita a outra escrita. (2004, p. 69).

Novamente, qual escrita? Será que é "destino" da escrita o fato de somente poder produzir-se por um ponto de interrogação, tal como a caricatura/quadro de Joyce $?^{17}$ Por Enigma? Lacan, no Seminário, Livro 23 , nos diz que "Vale a pena nos determos nisso. Joyce como escritor por excelência do enigma não seria a conseqüência da cerzidura tão malfeita desse ego, de função enigmática, de função reparadora?" (2007, p.
150). Sabemos que a escrita de Joyce o era em especial - a de um escritor que faz um manejo singular com a língua(s) (alíngua) - o que nos conduz a uma outra questão: o funcionamento de Joyce como escritor permite-nos estabelecer uma homologia com o funcionamento da escrita (écriture) na psicanálise e, a partir daí, derivarmos uma função da escrita enquanto tal? Vejamos o que nos diz Lacan:

As pessoas escrevem suas recordações de infância. Isso tem conseqüências. É a passagem de uma escrita para outra escrita. A psicanálise é outra coisa. Ela passa por um certo número de enunciados. Não está dito que ela leva à via de escrever. (...) Não está de modo algum definido que, com a psicanálise, vai se conseguir escrever. Para falar propriamente, isso supõe uma investigação a propósito do que significa escrever. (2007, p. 143).

Tomando ao pé da letra, "isso supõe uma investigação do que significa escrever", o que nos remete, novamente, à função do enigma. Porém, a citação acima estabelece uma heterogeneidade que é preciso marcar: de um lado, trata-se de uma escrita para outra escrita; de outro, trata-se de uma escrita que produz enigmas. Ao se perguntar em que consiste o enigma, Lacan responde: é a arte das entrelinhas. Seguindo, ainda, seu raciocínio, temos que "A escrita me interessa, posto que penso que é por meio desses pedacinhos de escrita que, historicamente, entramos no real, a saber, que paramos de imaginar. A escrita das letrinhas matemáticas é o que suporta o real." (2007, p. 66). Enigmático, talvez! Mas, é Lacan quem diz, no Livro 20: Mais, ainda, que

Há uma coisa que é ainda mais certa - acrescentar a barra à notação $\mathrm{S}$ e s já é algo de supérfluo, senão fútil, na medida em que o que ela faz valer já está marcado pela distância da escrita. A barra, como tudo o que é da escrita, só tem suporte nisto - o escrito, não é algo para ser compreendido (1985, p. 48).

Até onde ir? Até onde ir em busca de um sentido que está apenas implícito é enigma, está nas entrelinhas? Será que o enigma seria interpretável? Parece que uma coisa é a escrita, outra é o que se pode dizer dela. Talvez, para fazer sentido, é preciso que algo de nós esteja aí colocado. Entretanto, não podemos ser ingênuos a ponto de buscar alguma certeza acerca da escrita.

Ao procurar fazer o entrelaçamento entre Pessoa, Lacan e a escrita, o algo a ser colocado, neste texto, é o Escrever sobre o escrever. De Pessoa sobre pessoa Socego - Só e Cego. Sem remeter a algo mais.

\section{Sobre os respingos - Escrever sobre o escrever}

Creio que a escrita deste texto não nos permite mais continuar com a hipótese de que há um "sujeito da escrita". Há, apenas, um sujeito que escreve - tal- 
vez, como Pessoa, como Joyce, como Llansol, como Bispo do Rosário, como muitos que da escrita se servem procurando, nesse ato, inscrever-se. Porém, não podemos esquecer que, nesse texto, o sujeito é a pessoa do Encoberto, do Desejante. Ao duplicarmos essas expressões, retirando-lhes as maiúsculas, teremos: Encoberto/encoberto; Desejante/desejante, com uma barra que as separa, o que produz um desdobramento, do sujeito e da escrita - do escrever sobre o escrever. Não é isto que se pede em uma escrita escolar? Pede-se que o sujeito escreva - aprenda a escrever - as letras, as palavras, o texto. Paradoxalmente, o que se pede já estava lá (escritura), antes que o sujeito aprendesse a escrita legível/gráfica. Pede-se, então, paradoxalmente, que um escrito retroaja sobre o outro, a posteriori, a fim de produzir algo que já estava lá no "início“. Para isso, entretanto, é preciso um leitor. No começo deste texto, nos fizemos acompanhar de Borges e recortamos a metáfora da caverna mágica cheia de mortos. Ressaltamos que seria necessário ressuscitar os mortos por meio do "leitor certo". Talvez não possamos mais, também, contar com a hipótese do "leitor certo" O leitor é sempre torto, opera por desvios e por recortes, nunca estando no lugar "certo". O escrito, a escrita - assim como a leitura -, colocam em causa o sujeito e sua singularidade, que só advêm através de um ato solitário.

\section{Só e cego}

Recomponho a palavra - Desassossego - com o Encoberto da escrita, com o Desejante que se intromete nas entrelinhas, com a própria criação, já que, depois de ter escrito, o sujeito nela não se reconhece e sobre ela não pode mais escrever. Pessoa não pode fazer dos seus escritos, ele próprio, uma obra; Lacan começou tarde a escrever sobre a escrita - obra de sonho.

Desassossego, criação, escrita, sonho, jogo das letras. Walter Benjamim, no livro Obras Escolhidas IIRua de Mão Única, nos fala sobre O Jogo das Letras.

(...) nada desperta em mim mais saudade que o jogo das letras. (...). A saudade que em mim desperta o jogo das letras prova como foi parte integrante de minha infância. O que busco nele na verdade, é ela mesma: a infância por inteiro, tal qual a sabia manipular a mão que empurrava as letras no filete, onde se ordenavam como uma palavra. A mão pode ainda sonhar com essa manipulação, mas nunca mais poderá despertar para realizá-la de fato. Assim, posso sonhar como no passado aprendi a andar. Mas isso de nada adianta. Hoje sei andar; porém, nunca mais poderei tornar a aprendê-lo. (1997, p. 105).

Podemos, pelo menos, continuar tentando escrever, mesmo que seja Escrever sobre o escrever. Isto é pouco e, ao mesmo tempo, é muito. Talvez já não possamos mesmo aprender o jogo das letras, mas com alguns respingos de criação ainda é possível sonhar.

\section{Notas}

1 Sobre a origem da escrita, tema que abordaremos somente de forma tangencial, ver: MORRISON, Ken e Outros. (1995) Cultura, Pensamento e Escrita. São Paulo: Editora Ática; A "Conjectura de Lacan” sobre a origem da escrita. In: ALLOUCH, Jean (1995). Letra a Letra. Traduzir, Transcrever, Transliterar. Rio de Janeiro: Campo Matêmico. POMMIER, G. (1993) Naissance et renaissance de l'écriture. Paris: PUF. FÉVRIER, J. (1995). Histoire de L'Écriture. Paris: Payot. Como curiosidade, ver ROUSSEAU, Jean-Jacques (1981). Ensaio sobre a origem das línguas. Lisboa: Editorial Estampa. GELB, I. J. (1973). Pour une Théorie de L'Écriture. Paris: Flammarion.

2 Remeto o leitor a LACAN, Jacques. (1996) O Seminário Livro 7: A ética da psicanálise. Rio de Janeiro: Jorge Zahar.; STEINER, George. (2003). Gramáticas da criação. São Paulo. Globo.

3 Na verdade, são escritos lingüísticos dispersos que foram reunidos em um livro, o qual se intitula A lingua portuguesa (1999). No que diz respeito ao anseio de Pessoa, nestes escritos, de fundar uma língua universal, creio que só podemos ler como algo da ordem mítica, tal como ele mesmo nos aponta nos escritos que abrem este texto - Desejo ser um criador de mitos (...).

4 Coloco subjetivação entre aspas em virtude do abuso lingüístico/teórico de que tal nominação tem sido alvo. Quando se afirma que tudo é processo de subjetivação, o que acontece é que nada é processo de subjetivação. Talvez tenhamos que exaurir o termo até que "ele" nos mostre a que veio. Descascar a palavra até o osso, diriam alguns; transformá-la em transsubjetivação, diriam outros. No último caso, está em questão um processo de ultrapassamento da subjetivação (relação eu-tu), requerendo, nesse caso, que se instale um processo enunciativo que implica três instâncias (eu-tu-ele), onde o terceiro termo, ele, seria a garantia do processo enunciativo e, portanto, indicaria a trans-subjetivação. $\mathrm{O}$ tema requer ainda muitos estudos.

5 Para sermos mais justos, estamos nos referindo aqui a uma certa tradição filosófica, a qual evoca a imagem de uma identidade cartesiana unificada ou uma espécie de centro da subjetividade.

6 Encontramos uma fotografia do quadro de James Joyce no livro de LAIA, Sergio. (2001) Escritos fora de si: Joyce, Lacan e a loucura. Belo Horizonte: Autêntica/FUMEC.

7 Sobre a questão da escritura em Benjamim, ver o texto Walter Benjamim e os sistemas de Escritura. In: SELIGMANNSILVA, Márcio (2005). O Local da Diferença. São Paulo: Ed. 34.; BENJAMIM, Walter. (1984) A origem do Drama Barroco Alemão. São Paulo: Brasiliense.

8 Não vamos encontrar de forma sistemática e em uma obra só o que seria correspondente a uma teoria da escrita em Lacan. Por mais que Lacan, no Seminário - Livro 23, diga que começou a sonhar após consumir muitas histórias de escrita, e mesmo de teorias da escrita, sabemos, segundo suas próprias palavras, ou melhor, por suas queixas, que era um pouco tarde - "Você começou um pouco tarde”. (p. 533) In: Lacan, Jacques. (1998) Escritos. Rio de Janeiro: Jorge Zahar. 
9 Trata-se de um livro inédito, um corpo desorganizado, fragmentado, em embrião, quando da morte do poeta. Vejamos o que diz Babo: A virtualidade do livro confere-lhe uma dimensão particular, já que, a sua publicação, finalmente em 1982, conheceu o estatuto para o qual estava destinado, o de advir como livro. Tal como os Essais de Montaigne ou Lê Livre de Mallarmé, o Livro do Desassossego é uma obra dificil de classificar por fugir aos gêneros a que aparentemente estaria confinada. Tratando-se de um conjunto de textos heterogêneos constituidos tanto por pensamentos ou máximas como por pedaços de narrativa que mistura o ficcional e o autobiográfico, com flashes do quotidiano e da Lisboa antiga, esta obra não chegou a sê-lo, dado justamente este carácter heterogéneo e embrionário, um projecto mais que uma obra. (1993; p. 163).

10 Para Lacan, "O desejo é uma relação do ser à falta. Essa falta é falta de ser (manque d'être) propriamente dita. Ela não é falta disto ou daquilo, mas falta de ser através da qual o ser existe". Ainda: "Ele é fundamentalmente sem objeto, desejo de nada nomeável" (p. 261). LACAN, Jacques. (1985) $O$ Seminário - Livro II: O eu na teoria de Freud e na técnica da psicanálise. Rio de Janeiro: Jorge Zahar. Ler Pessoa por Lacan? Resta saber se a nominação Desejante é intercambiável. O D maiúsculo está mais para enigma, para uma convocação do outro, para que ali coloque a sua própria tinta.

11 O conceito de escritura, tal como já assinalamos no corpo do texto, foi trabalhado tanto por Lacan, Derrida como por Barthes e, em que pese a heterogeneidade entre os autores, eles parecem estabelecer algumas diferenças com relação ao termo escrita. Nesse sentido, ver as seguintes obras: DERRIDA, Jacques. A escritura e a diferença. São Paulo: Perspectiva, 1971; BARTHES, Roland. O prazer do texto. São Paulo: perspectiva, 1977; _. Oral/Escrito; Escrita. In: Enciclopédia Einaudi. Oral/Escrito e Argumentação. Imprensa Nacional - Casa da Moeda, 1987. LACAN, Jacques. O Seminário - Livro 20: mais, ainda. Rio de Janeiro: Zahar, 1985; _. Le Séminaire - Livre 18 (Não traduzido); _. Escritos. São Paulo: Perspectiva, 1978; REGO, Claudia Moraes. Traço, Letra, Escrita: Freud, Derrida, Lacan. Rio de Janeiro: 7 Letras, 2006; entre outros. No que diz respeito à psicanálise, Lacan mais propriamente, sabemos que ele pode apreender como a letra, enquanto traço e enquanto resto, sustenta, no ponto radical da escritura, a constituição de um sujeito.

12 Alguns livros que procuram cingir a escrita: PORTUGAL, Ana Maria. O vidro da palavra. Belo Horizonte: Autêntica, 2006; RIVERA, Tania. Guimarães Rosa e a Psicanálise: Ensaios sobre imagem e Escrita. Rio de Janeiro: Jorge Zahar, 2005; MARTENDAL, Adriano. A escrita no limiar do sentido. São Paulo: Escuta, 2007.

13 Para Branco, Felizmente, para nós, há o véu da beleza, último anteparo ante o horror do Real, como diria Lacan, a recobrir a cicatriz dessa escritura e a repetir, no momento em que a tememos mais, que a escrita e o medo são incompatíveis. (2000; p. 54). In: BRANCO, Lúcia Castello. Os absolutamente sós: Llansol - A letra - Lacan. Belo Horizonte: Autêntica, 2000.

14 Para Blanchot, De fato, revelar supõe que se mostre algo que não aparecia. A palavra (pelo menos a que interessa: a escrita) desnuda, sem mesmo retirar o véu, e às vezes, ao contrário (perigosamente), encobrindo - de uma maneira que não cobre nem descobre. (p. 69). BLANCHOT, Maurice.(2001) A conversa infinita - A palavra Plural. São Paulo: Escuta.
15 Para Babo, tal divisão produz "A estranha inquietação da solidão e da desmultiplicação do eu em outros-estranhos, mas também a da cegueira, sublinhada pelo prefixo de negação que abre o significante em espaço de ambigüidade, em infinidade de possiveis já que, tratando-se de uma denegação, o título (do livro) dirá justamente o que quer calar: uma escrita catártica, remédio contra a solidão e a cegueira. (1993; p. 170-171). Se Pessoa diz que este livro é minha cobardia, talvez possamos pensar que a catarse escrita não produz os efeitos que dela espera o sujeito. (Idem).

16 Para Melman, "Talvez pudéssemos lembrar que estamos partindo de uma prática que é a da fala, isto é, que é organizada pelo significante, e que estamos descobrindo por ocasião dessa prática essas manifestações do inconsciente que são, elas, organizadas pela letra. Como se já houvesse, então, na organização psíquica, o depósito de uma escrita. E essa escrita, nesse caso, mostra-se portadora do que é o desejo, que escapa ao locutor, como sabemos, e essa característica parece bem especifica para que Lacan faça da própria escrita esse elemento do qual ele diz que é fadado à poubellication, isto é, que ele faça do conjunto da escrita o que é, pelo mecanismo da linguagem, rejeitado, excluido, numa posição que põe a letra em função de ser o suporte do desejo. "(2004; p. 15)

17 Anquetil (2004), ao perguntar-se sobre o estatuto dado pelo psicanalista ao escrito de um paciente, pergunta-se se todo escrito pode ser assimilado a uma tentativa de se dar um nome próprio. Assim, "Da escrita de Joyce à grafomania do psicótico, de que falará Charles Melman, há um passo. Nem toda escrita, portanto, me parece fazer sinthoma, como no caso de Joyce analisado por Lacan. Talvez fosse preciso voltar às suas numerosas reflexões sobre a literatura, a literatura que faz borda, que é litoral. (p. 43).

\section{Referências Bibliográficas}

Anquetil, N. (2004). Saussure e Lacan. In C. Melman et al. (Orgs.), O significante, a letra e o objeto (pp. 35-40). Rio de Janeiro: Companhia de Freud.

Babo, M. A. (1993). A escrita do livro. Lisboa: Ed. Vega.

Benjamim, W. (1997). Obras Escolhidas II - Rua de mão única. São Paulo: Brasiliense.

Borges, J. L. (2000). Esse oficio do Verso. São Paulo: Companhia das Letras.

Branco, L. C. (2000). Os absolutamente sós: Llansol - A letra - Lacan. Belo Horizonte: Autêntica.

Darmon, M. (2004). Ravinamento. In C. Melman et al. (Orgs.), O significante, a letra e o objeto. Rio de Janeiro: Companhia de Freud.

Gagnebin, J. M. (2006). Lembrar escrever esquecer. São Paulo: Ed. 34.

Lacan, J. (1985). O Seminário, Livro 20: Mais, ainda. Rio de Janeiro: Jorge Zahar.

Lacan, J. (1998) Escritos. Rio de Janeiro: Jorge Zahar.

Lacan, J. (2003) Outros Escritos. Rio de Janeiro: Jorge Zahar.

Lacan, J. (2007). O Seminário, Livro 23: O sinthoma. Rio de Janeiro: Jorge Zahar.

Melman, C. (2004). A fobia da escrita. In C. Melman et al. (Orgs.), O significante, a letra e o objeto. Rio de Janeiro: Companhia de Freud.

Pessoa, F. (1990). O Livro do Desassossego. Lisboa: Editorial Presença. 
Pessoa, F. (1999) A Lingua portuguesa. São Paulo: Companhia das Letras.

Quilichini, J. (2004). O significante, a letra e o objeto: articulações. In C. Melman et al. (Orgs.), O significante, a letra e o objeto. Rio de Janeiro: Companhia de Freud.

Tellerman, E. (2004). Intervenção. In C. Melman et al. (Orgs.), O significante, a letra e o objeto. Rio de Janeiro: Companhia de Freud.

Zizek, S. \& Daly, G. (2006). Arriscar o impossível-Conversas com Zizek. São Paulo: Martins Fontes.

Margareth Schäffer é mestre em Educação (1988) e doutora em Educação (1995) pela Universidade Federal do Rio

Grande do Sul. Atualmente é professora titular da Faculdade de Educação da UFRGS e do Programa de Pós-Graduação em Educação, desenvolvendo seminários na área de educação e psicanálise; Subjetividade e linguagem; Escrita e Criação; Pesquisa em educação e psicanálise, entre outros.

Email: margareth.schaffer@ufrgs.br

\section{Escrever sobre o escrever}

Margareth Schäffer

Recebido: 01/07/2008

Aceite em: 08/10/2008 